\title{
Description
}

\section{'Arota': A New Interspecific Hybrid Pistachio Rootstock}

Mohammad Akbari

Department of Horticultural Sciences, Faculty of Agriculture, University of Tabriz, Tabriz, Iran; and Nazari Business Group, Tehran, Iran

Hossein Hokmabadi

Department of Horticulture, Agricultural Research Education and Extension Organization (Areo), Tehran, Iran

\section{Mohsen Heydari \\ Department of Horticulture, College of Agriculture, University of Shahed, Tehran, Iran \\ Ali Ghorbani \\ College of Agriculture, Islamic Azad University Marvdasht, Branch Fars, Iran}

Additional index words. Iran, $P$. integerrima $\times P$. atlantica, vigorous
Vigor and rapid growth are among the primary breeding objectives for pistachio rootstocks (Sheikhi et al., 2019), particularly in a rootstock grafted to a scion with the extended juvenility of the current Pistacia vera commercial pistachio scions. Arota is a new Iranian interspecific hybrid (Pistacia integerrima $\hat{\alpha} \times$ Pistacia atlantica ) pistachio rootstock selected from the progeny of 222 controlled crosses made in 2013 and 2014. Of these crosses, the most vigorous seedlings were evaluated for 4 years for growth relative to the University of California Berkeley seedling rootstock (UCB) - a $P$. integerrima $\hat{\sigma} \times P$. atlantica + hybrid using different individuals of the same species (Ferguson and Haviland, 2016). Of the 222 seedling F1 hybrids, 16 had statistically significant better height and diameter growth relative to UCB1. The 16 seedlings achieved a diameter sufficient for T-budding within 5 to 7 months from seed germination that could facilitate orchard establishment within the first year of rootstock growth (Fig. 1).
Received for publication 8 Jan. 2020. Accepted for

Published online 13 May 2020.

We gratefully acknowledge the financial support of thank the project participants: Jalal Masoumi, Alireza Assadollahi, Ali Karami, Amin Ariyaei, Hamed Akbari, Abolfazl Abkar, Hossein Barkhordari, Ahmad Akhyani, Khair Mohammad Mohammadi, Malihe Saberi, and Ebrahim Hashemi. We also thank Louise Ferguson and Abdollatif Sheikhi for comments and revisions.

M.A. is the corresponding author. E-mail: mohammad akbari@ut.ac.ir.

This is an open access article distributed under the CC BY-NC-ND license (https://creativecommons. org/licenses/by-nc-nd/4.0/). publication 26 Mar. 2020 Nazari Business Group and Mr. Ali Nazari. We

\section{Origin}

A total of 222 controlled crosses were made using 37 female $P$. atlantica and six male $P$. integerrima trees. The pollen of all six male trees was applied to the receptive flowering rachii of the 37 female trees. Each cross was made on three separate branches within each female tree, producing a total 18 branches on each female tree and a total of 666 pollinations for the 222 crosses. Although both of the selected parents producing Arota are heterozygous, the resulting hybrid seedlings displayed a marked uniformity among the crosses (Fig. 2). The name Arota is a combination of the names of the companies that made the hybridizations and evaluated the F1 hybrids: Arezobahar (ARO) and Tat (TA).
Within the first 2 years of evaluation for seed germination, and as unbudded rootstocks for height and diameter growth relative to the unbudded control rootstock (UCB1), 16 of the of 222 hybrids were evaluated for an additional 2 years, for a total of four consecutive years. The average germination percentage of Arota seeds was $91.6 \%$ vs. $75.5 \%$ for UCB 1 . In a complete randomized design, the height and diameter of Arota and 15 other selections were compared with UCB1. Duncan's multiple range test was applied to compare the mean values obtained (Table 1). At 4 years, Arota's average height was $81.5 \mathrm{~cm}$ compared with 59.4 $\mathrm{cm}$ for UCB1. Arota's average diameter was $5.3 \mathrm{~cm}$ vs. UCB1's $4.2 \mathrm{~cm}$. All 16 hybrid selections had a statistically significantly better height and girth growth compared with UCB1, with the Arota selection having the best growth (Table 1).

Arota has three to four main roots, with multiple fibrous lateral roots. The root architecture appears to be a combination of UCB1 and $P$. vera, the most common Iranian rootstock (Akbari et al., 2018). The leaves of Arota are similar to UCB1 - pinnately compound leaves composed of 13 to 19 leaflets.

During first year in the ground, six different female scion cultivars-Akbari, Fandoughi, Ahmad-Aghaei, Qazvini, Razavi, and Chorook-were T-budded on Arota and UCB1 in a randomized complete block design with four replications. Arota demonstrated statistically significantly better grafting success with four of the six scions, and equal success with the other two scions. Arota had an average 79\% average grafting with the Akbari, Ahmad-Aghaei, Fandoughi, and Qazvini cultivar scions, significantly greater than the $53 \%$ obtained for the UCB1 rootstock. With two cultivars, Razavi and Chorook scions, field T-budding success was
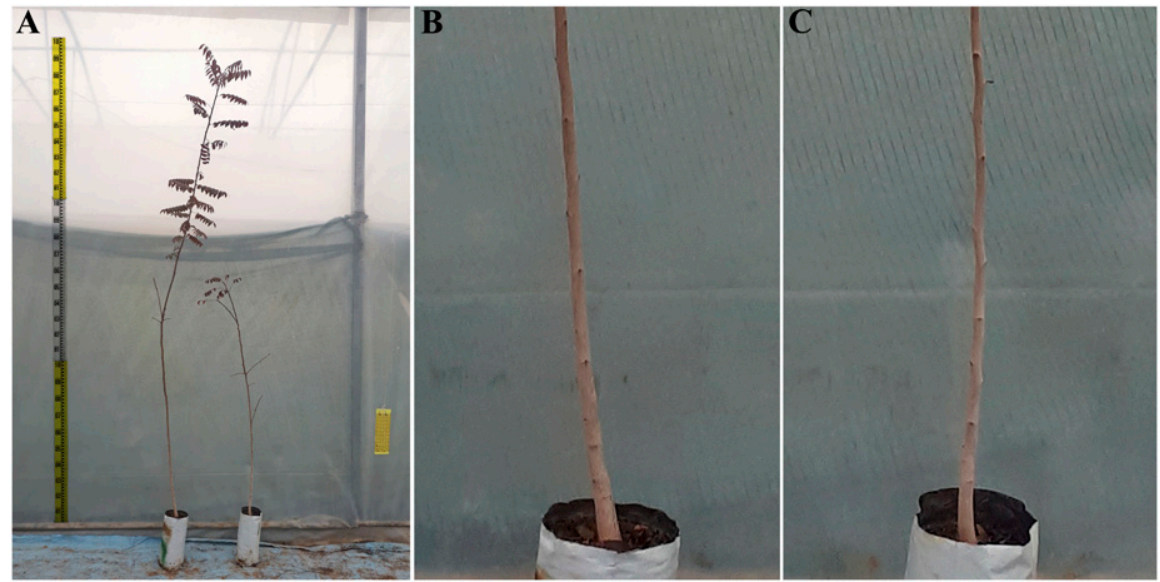

Fig. 1. (A) One-year-old Arota pistachio hybrid rootstock (left) with a 2.95-m height compared with 1-year-old UCB1 on the right with a 1.55-m height. Trunk diameter comparison of (B) the same 1-year old Arota $(155 \mathrm{~mm})$ and $(\mathbf{C}) \mathrm{UCB} 1(955 \mathrm{~mm})$. 


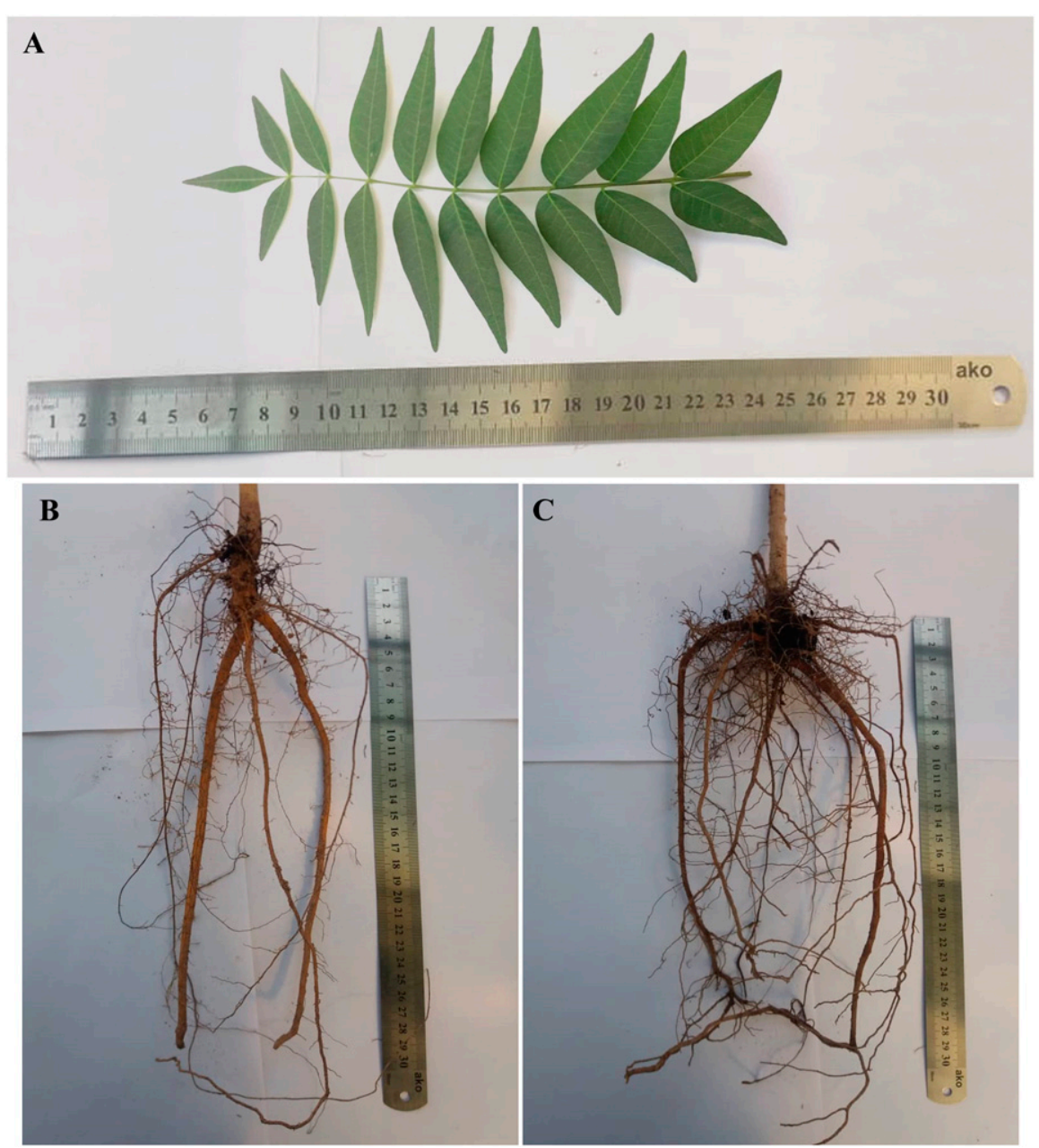

Fig. 2. (A) The leaves of 1-year old Arota. (B) The roots of 1-year old Arota rootstock. (C) The roots of 2-year-old Arota rootstock grown in greenhouse conditions.

Table 1. Comparison of germination percentage, height, and girth of 5-month-old seedlings of the 16 interspecific hybrids relative to UCB1 in a complete randomized design and using Duncan's multiple range test to determine mean separation.

\begin{tabular}{lccc}
\hline Hybrids & Germination $(\%)$ & $\mathrm{Ht}(\mathrm{cm})$ & Diam $(\mathrm{mm})$ \\
\hline Arota & $91.6 \mathrm{a}$ & $81.5 \pm 10.1 \mathrm{a}$ & $5.3 \pm 0.5 \mathrm{a}$ \\
A2 & $90.3 \mathrm{a}$ & $77 \pm 15 \mathrm{bcd}$ & $4.7 \pm 0.74 \mathrm{bcd}$ \\
A3 & $87 \mathrm{bc}$ & $70 \pm 12 \mathrm{gh}$ & $4.5 \pm 0.79 \mathrm{def}$ \\
A4 & $89.6 \mathrm{ab}$ & $72 \pm 12.2 \mathrm{efg}$ & $4.3 \pm 0.7 \mathrm{fg}$ \\
A5 & $87.3 \mathrm{bc}$ & $72.8 \pm 17.2 \mathrm{defg}$ & $4.6 \pm 0.9 \mathrm{cde}$ \\
A6 & $75.4 \pm 12.9 \mathrm{bcde}$ & $4.7 \pm 0.7 \mathrm{bc}$ \\
A7 & $69 \pm 15.45 \mathrm{gh}$ & $4.6 \pm 0.97 \mathrm{cde}$ \\
A8 & $89 \mathrm{ab}$ & $67.4 \pm 13.3 \mathrm{~h}$ & $4.7 \pm 0.8 \mathrm{bcd}$ \\
A9 & $87 \mathrm{bc}$ & $72.2 \pm 15.7 \mathrm{efg}$ & $4.9 \pm 1 \mathrm{~b}$ \\
A10 & $80.5 \mathrm{~d}$ & $77.6 \pm 14 \mathrm{abc}$ & $4.6 \pm 0.7 \mathrm{bcde}$ \\
A11 & $68.8 \mathrm{e}$ & $69.1 \pm 14 \mathrm{gh}$ & $4.5 \pm 0.5 \mathrm{cde}$ \\
A12 & $72.3 \mathrm{e}$ & $74.5 \pm 16 \mathrm{gh}$ & $4.4 \pm 0.7 \mathrm{ef}$ \\
A13 & $58.4 \mathrm{f}$ & $75.1 \pm 11.2 \mathrm{cdef}$ & $4.7 \pm 0.9 \mathrm{bc}$ \\
A14 & $53.2 \mathrm{f}$ & $75.3 \pm 14 \mathrm{bcde}$ & $4.7 \pm 0.7 \mathrm{bcd}$ \\
A15 & $51.9 \mathrm{f}$ & $78.2 \pm 18.7 \mathrm{abc}$ & $4.6 \pm 0.9 \mathrm{cde}$ \\
A16 & $51.1 \mathrm{f}$ & $59.4 \pm 16 \mathrm{i}$ & $5.1 \pm 0.9 \mathrm{a}$ \\
UCB1 & $20.5 \mathrm{~g}$ & & $4.2 \pm 0.6 \mathrm{~g}$ \\
\hline
\end{tabular}

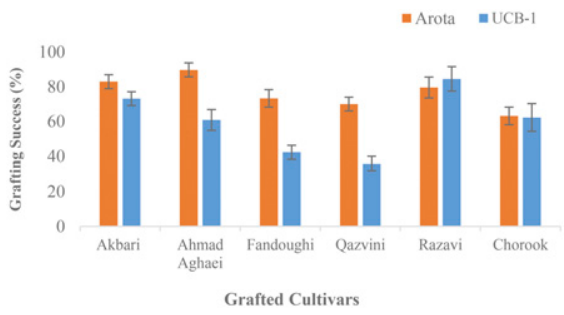

Fig. 3. Mean comparisons of grafting success (percentage) of six scion cultivars on Arota and UCB1 rootstock. The Akbari, AhmadAghaei, Fandoughi, and Qazvini cultivars had statistically significant better grafting success on Arota vs. grafting on the UCB1 rootstock. The Razavi and Chorook cultivars had equal grafting success on both the Arota and UCB1 rootstocks.

equally successful, averaging at $71 \%$ on Arota and $73 \%$ on UCB1 (Fig. 3).

Long-term trials investigating tolerance of biotic and abiotic stress, growth, and yield of some cultivars of the Arota and control $\mathrm{UCB} 1$ rootstocks are now in progress. The experimental hypothesis is that the better growth and vigor demonstrated by Arota will also produce a better early and full-bearing yield, and will demonstrate cold and salinity tolerance.

\section{Availability}

Limited quantities are available for research purposes, with priority given to universities and research centers, from the Research Department of the Nazari Business Group, PISTAT institute (www.pistat.co, www.pistat.ir).

\section{Literature Cited}

Akbari, M., N. Mahna, K. Ramesh, A. Bandehagh, and S. Mazzuca. 2018. Ion homeostasis, osmoregulation, and physiological changes in the roots and leaves of pistachio rootstocks in response to salinity. Protoplasma 255:13491362.

Ferguson, L. and D. Haviland. 2016. Pistachio production manual. Univ. of California, Agriculture \& Natural Resources, Davis, CA.

Sheikhi, A., M.M. Arab, P.J. Brown, L. Ferguson, and M. Akbari. 2019. Pistachio (Pistacia spp.) breeding, p. 353-400. In: J.M. Al-Khayri, S.M. Jain, and D.V. Johnson (eds.). Advances in plant breeding strategies: Nut and Beverage Crops. Springer, Switzerland. 